\title{
Helen Salisbury: Message in a bottle
}

\author{
Helen Salisbury GP \\ Oxford
}

The covid-19 pandemic has brought into sharp focus the need for care planning, especially with our older and frailer patients, for whom the benefits of hospital care need to be weighed against the risk of being cut off from family at the end of life. "Care planning" is sometimes seen as shorthand for a discussion about whether a patient would want to have cardiopulmonary resuscitation (CPR) in the event of a cardiac arrest. This can be a difficult conversation: apart from the danger of inducing fear and anxiety if we handle it poorly, we run the risk of giving a false impression of choice. Patients can choose not to have a treatment that may be offered, but they cannot insist on a treatment that doctors believe to be futile.

The last time we had a drive to complete care plans (part of a scheme called "admission avoidance"), the most useful part was updating the next of kin's contact details and finding out whether we could speak to them if the need arose. Some patients, particularly those with experience of multiple hospital admissions, have quite strong preferences for being cared for at home, even if it limits the medical interventions available. However, most patients, when asked about their preferred place of care, quite sensibly say, "Home if possible, hospital if necessary."

If patients do decide that they'd rather not have CPR this decision has to be conveyed to all relevant parties. In theory this should be relatively easy, in this age of coding and databases, but we don't have a joined-up system. Information sharing between hospitals and GPs on this issue is haphazard at best, and I sometimes learn about decisions only when I bring the subject up with my patient and am told, "Oh yes, doctor, we discussed that at the hospital."

When I fill in a Do Not Attempt CPR form, copies are sent to ambulance control and the out-of-hours service-but can I be confident that the relevant people will be able to access this information when it's needed? Where I work, the back-up system is the "message in a bottle." This consists of a sticker displayed by the patient's front door and a bottle, containing either the form or instructions about where to find it, kept in the fridge (on the grounds that most houses have only one fridge and it's easy to find). This usually works, but I'm conscious of the potential psychological and social burdens. If there's a sticker in your front window you may believe that all of your neighbours know that you're ill, on your last legs, and resigned to death. Every time you go to the fridge you may be reminded of your mortality or wonder whether you made the right decision.

We need better coding and information sharing (with patient consent) so that patients, having had these difficult conversations, can be confident that their wishes are known to the relevant services-ideally, without the whole street having to know as well.

\section{Competing interests: See www.bmj.com/about-bmj/freelance-contributors.}

Provenance and peer review: Commissioned; not externally peer reviewed.

Published by the BMJ Publishing Group Limited. For permission to use (where not already granted under a licence) please go to http://group.bmj.com/group/rights-licensing/ permissions 